\title{
KAJIAN EMPIRIS SUMUR RESAPAN PADA TANAH SILT
}

\author{
Edy Susilo ${ }^{1}$, Bambang Sudarmanto ${ }^{2}$, Bambang Purnijanto ${ }^{3}$ \\ ${ }^{1}$ Fakultas Teknik, Universitas Semarang \\ 123edysusilo@gmail.com \\ ${ }^{2}$ Fakultas Teknik, Universitas Semarang \\ bambangsudarmanto68@gmail.com \\ ${ }^{3}$ Fakultas Teknik, Universitas Semarang \\ aabamb@gmail.com
}

\begin{abstract}
Abstraksi : Pertumbuhan penduduk sebagai pemicu perubahan tataguna lahan memberikan dampak langsung terhadap peningkatan aliran permukaan dan menurunnya peresapan air ke dalam tanah, yang berakibat terjadinya banjir dan kekurangan air tanah. Sumur resapan salah satu alat untuk menambah peresapan air dan sekaligus menurunkan debit banjir. Pendekatan persamaan debit sumur resapan pada umumnya dilakukan secara matematis, sedangkan secara empiris masih sangat kurang.Tekstur tanah diinvestigasi dengan grain size dan hidrometer. Klasifikasi tanah dengan menggunakan segitiga tekstur tanah menurut USDA. Dengan menggunakan sumur dinding rapat diameter $50 \mathrm{~cm}$, dan tinggi $90 \mathrm{~cm}$ dilakukan pengujian debit resapan sumur sebanyak 6 kali dengan periode waktu awal 0 jam (tes-1), 3 jam (tes-2), 18 jam (tes-3), 24 jam (tes-4), 42 jam (tes-5), dan 24 jam (tes-6) dengan terus menerus sumur resapan diisi air tanpa terputus. Pengukuran debit resapan dilakukan dari kedalaman $85 \mathrm{~cm}$, setiap penurunan $5 \mathrm{~cm}$ sampai kedalaman $10 \mathrm{~cm}$. Diterimanya sebuah persamaan regressi dengan melihat koefisien korelasi $\left(R^{2}\right)$ mendekati 1.

Hasil penelitian debit sumur resapan dengan diameter 0,50 meter untuk tekstur tanah silt, mengikuti persamaan parabola $Q s=0,000001 . H^{4,487}$. Nilai $R^{2}$ untuk persamaan ini adalah 0,984. Debit resapan sumur resapan akan menurun semakin lama peresapan berlangsung. Tanah silt belum mencapai kondisi jenuh dalam waktu peresapan selama 24 jam. Diharapkan penelitian ini dapat bermanfaat dalam pengembangan ilmu pengetahuan khususnya bidang sumber daya air yang berhubungan dengan permasalahan debit resap sumur resapan. Penelitian ini masih sangat awal dalam menyimpulkan hubungan debit resapan dengan kedalaman air dan masih perlu dikembangkan dengan variasi jenis tanah, diameter dan jenis sumur resapan.
\end{abstract}

Kata kunci : Sumur resapan, tekstur tanah, silt

\begin{abstract}
Population growth as a driver of land-use change has a direct impact on rising surface flows and decreasing infiltration into the soil, resulting in flooding and water shortages. The absorption well is one of the tools to increase water infiltration and simultaneously decrease the flood discharge. The approach of the discharge well equation is generally done mathematically, while the empirical is still very less. The soil texture is investigated by grain size and hydrometer. Soil classification using a soil texture triangle according to USDA. Using well wall wells of diameter $50 \mathrm{~cm}$, and height $90 \mathrm{~cm}, \mathrm{a}$ well discharge well 6 times (0 test-1), 3 hours (test-2), 18 hours (test-3), 24 hours hour (4th test), 42 hours (test-5), and 24 hours (test-6) with continuous absorption wells filled with water without interruption. The measurement of absorption discharge is done from a depth of $85 \mathrm{~cm}$, each decrease $5 \mathrm{~cm}$ to a depth of $10 \mathrm{~cm}$. Acceptance of a regression equation by looking at the correlation coefficient (R2) approaches 1.

The results of discharge well discharge research with diameter 0.50 meters for silt soil texture, following parabolic equation $Q s=0,000001$. H 4,487. The value of $R 2$ for this equation is 0.984 . The absorption well discharge will decrease the longer the infiltration takes place. The silt soil has not reached saturation condition within 24 hours of impregnation. It is expected that this research can be useful in the development of science, especially the field of water resources related to the problems of absorption wells disposal. This research is still very early in concluding the relationship of absorption discharge with water depth and still need to be developed with variation of soil type, diameter and type of absorption well
\end{abstract}

Keywords: absorption wells, soil texture, silt 


\section{Pendahuluan}

Sumber air meliputi air tanah dan air permukaan yang digunakan untuk berbagai kepentingan dirasakan semakin menurun kapasitas maupun kualitasnya. Di sisi lain permasalahan banjir menjadi fenomena di berbagai kota di Indonesia. Pertumbuhan penduduk, perubahan tata guna lahan serta pengelolaan sumber daya air yang belum menyeluruh merupakan pemicu permasalahan tersebut. Perubahan ini berdampak langsung pada respon daerah aliran sungai (DAS) terhadap hujan. Limpasan permukaan meningkat dengan waktu konsentrasi yang makin singkat, di sisi lain pengisian air tanah menurun, aliran antara dan aliran dasar menjadi berkurang. Permukaan-permukaan kedap air yang bertambah dalam suatu DAS akan berpengaruh pada perpindahan air dalam daerah tersebut dan volume air yang tersedia (Rahman, 2008). Banjir dan kekurangan air menjadi fenomena di berbagai kota dalam pengelolaan sumber daya air. Berdasarkan perubahan koefisien pengaliran akibat pengalihan fungsi lahan dari hutan menjadi perkerasan jalan akan meningkatkan debit puncak banjir sebesar 9,5 kalinya (Suripin, 2004). Perubahan tataguna lahan yang terjadi pada DAS Waduk Darma dalam periode tahun 1991 sampai tahun 2008 berakibat meningkatnya debit aliran permukaan dan menurunnya debit aliran dasar (Arif, 2009). Apabila beberapa permasalahan tersebut tidak diatasi maka akan mengalami kesulitan nendapatkan air sebagai kebutuhan hidup baik untuk kepentingan rumah tangga, pertanian, industri, pariwisata dan lain-lain, selain itu bahaya banjir akan mengancam setiap tahun. Salah satu usaha penyelamatan sumber air, maka diperlukan adanya proteksi terhadap sumber air tersebut agar keberadaannya dapat berkelanjutan melalui kegiatan konservasi tanah dan air dengan cara agronomi, mekanis, kimiawi, dan korservasi air. Peresapan air permukaan ke dalam sumur resapan merupakan salah satu cara yang sangat mudah dilakukan, terutama di daerah perkotaan dengan kedalaman air tanah yang tidak terlalu dangkal. Sumur resapan (SR) menyelesaikan masalah genangan dengan meresapkan air hujan kedalam tanah disekitar permukiman secara individual maupun komunal. SR dikembangkan mulai tahun 1980an ketika masalah lingkungan hidup menjadi perhatian global dengan di mulainya era sustainable development. Persamaan debit resapan SR pada umumnya dikembangkan berdasarkan pendekatan matematis, adapun pendekatan secara empiris perlu dilakukan penelitian.

\section{Tujuan Penelitian}

Penelitian ini bertujuan untuk mendapatkan persamaan empiris sumur resapan yang sederhana dan mudah diaplikasikan untuk kebutuhan konservasi air.

\section{Tinjauan Pustaka}

SR merupakan salah satu bangunan untuk pelestarian air, yang berfungsi untuk mengurangi debit aliran permukaan sekaligus untuk menambah infiltrasi air ke dalam tanah. Himpunan Mahasiswa Teknik Lingkungan (HMTL) ITB merumuskan model sumur resapan berdasarkan pada asas keseimbangan statis yang dibangun berdasarkan formulasi empiris yang menghitung dimensi sumur resapan menurut konsep V. Breen bahwa hujan terkonsentrasi adalah $90 \%$ dan konsep Horton bahwa air yang meresap alami adalah sebesar $30 \%$ jadi yang harus diresapkan adalah sebesar $70 \%$ dengan persamaan:

$$
\mathrm{H}=\frac{\mathrm{A}_{\mathrm{t}} \times 0,7 \times 0,9 \times R^{24 \mathrm{j}}-\left\{\left(\frac{\pi}{4 \mathrm{~d}^{2}}\right)\left(\frac{179}{\sqrt{\mathrm{p}}}\right) / 6\right\}}{\frac{\pi}{4 \mathrm{~d}^{2}} \times 1000}
$$




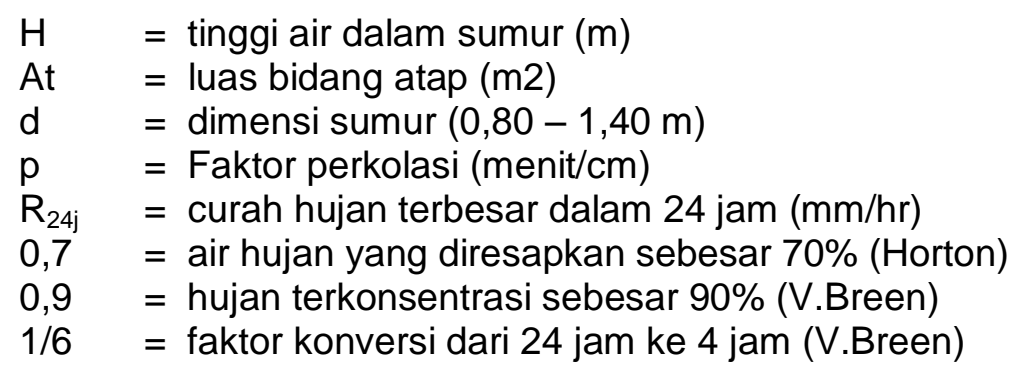

Persamaan di atas merupakan pendekatan umum. Peresapan air hujan ke dalam tanah tergantung jenis tanah sedangkan hujan yang terkonsentrasi ke dalam sumur tergantung desain dan sistem drainasi yang dibangun. Dengan konversi sebesar 1/6 diasumsikan durasi hujan selama 4 jam yang pada kenyataannya tidak selalu demikian. Faktor perkolasi tidak mudah didapatkan secara visual.

Pusat penelitian dan Pengembangan Permukiman Departemen Pekerjaan Umum (DPU, 1991) telah menyusun standar tata cara perencanaan teknis sumur resapan air hujan untuk lahan pekarangan yang dituangkan dalam SK SNI 06-2405-1991. Formula ini dibangun berasaskan keseimbangan statik sebagaimana persamaan:

$$
\mathrm{H}=\frac{\mathrm{A}_{\mathrm{t}} \mathrm{IT}-\mathrm{A}_{\mathrm{S}} \mathrm{KT}}{\mathrm{A}_{\mathrm{S}}+\mathrm{PKT}}
$$

Dimana:

$\mathrm{H} \quad=$ kedalaman/tinggi air dalam sumur $(\mathrm{m})$

I = intensitas hujan ( $\mathrm{m} / \mathrm{jam}$ )

$A_{t} \quad=$ luas tadah, berupa luas bidang atap atau permukaan yang diperkeras $\left(\mathrm{m}^{2}\right)$

$A_{s} \quad=$ luas tampungan sumur $\left(\mathrm{m}^{2}\right)$

$\mathrm{P} \quad=$ keliling sumur $(\mathrm{m})$

$\mathrm{K}=$ koefisien permeabilitas tanah $(\mathrm{m} / \mathrm{jam})$

$\mathrm{T} \quad=$ durasi hujan (jam)

$\mathrm{R} \quad=$ Radius sumur $(\mathrm{m})$

Persamaan di atas mengasumsi seluruh curah hujan masuk ke dalam sumur resapan, jenis tanah homogen, dinding sumur kedap, intensitas hujan tetap, dan laju infiltrasi sumur resapan dianggap konstan.

Rumus dasar resapan di dalam tanah dikemukakan oleh Forchheimer (1930) sebagai berikut:

$$
\mathrm{q}_{0}=\mathrm{FKh}
$$

dengan:

qo = debit infiltrasi (m3/detik)

$\mathrm{F} \quad=$ faktor bentuk bangunan resapan $(\mathrm{m})$

$\mathrm{K}=$ permeabilitas tanah ( $\mathrm{m} /$ detik)

$\mathrm{h} \quad=$ kedalaman air $(\mathrm{m})$ 


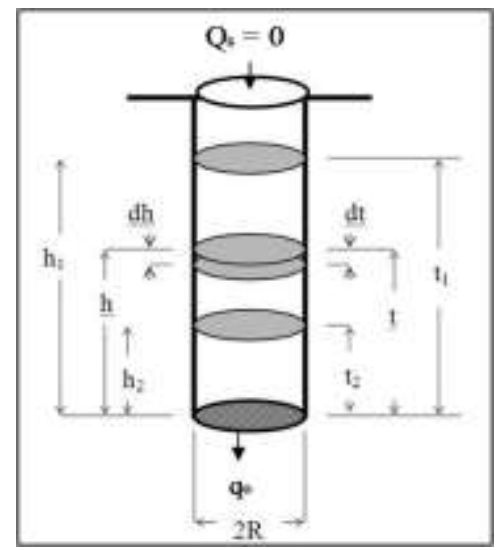

Gambar 1. Sketsa debit dan kedalaman air di dalam SR

Air di dalam SR seperti pada Gambar 2.2 semula dengan kedalaman $h_{1}$ pada waktu $t_{1}$, setelah waktu $t_{2}$ karena resapan sebesar $q_{0}$ dan tidak ada debit yang masuk kedalaman menjadi $h_{2}$. Untuk perubahan $\Delta \mathrm{h}$ selama waktu $\Delta \mathrm{t}$, debit yang meresap sebesar:

$$
\mathrm{dq}_{0}=\mathrm{A}_{\mathrm{s}} \frac{\mathrm{dh}}{\mathrm{dt}}
$$

Perubahan volume yang terjadi bila ada debit masuk sebesar $Q_{\mathrm{s}}$ mengakibatkan perubahan kedalaman $\mathrm{h}$ dalam waktu $\mathrm{t}$ adalah:

$$
\begin{aligned}
& \mathrm{dV}=\left(\mathrm{Q}_{\mathrm{s}}-\mathrm{FKh}\right) \mathrm{dt} \\
& \mathrm{dV}=\mathrm{A}_{\mathrm{s}} \mathrm{dh}
\end{aligned}
$$

Dari 2 persamaan untuk $t_{1}=0$ dan $h_{2}=0$, maka $t_{2}=t$, dan $h_{2}=h$, maka persamaan di atas menjadi (Sunjoto, 1989b):

$$
\mathrm{Q}_{\mathrm{s}}=\frac{\mathrm{F} \cdot \mathrm{K} \cdot \mathrm{h}}{\left[1-\mathrm{e}^{\frac{-\mathrm{FKt}}{\mathrm{A}_{\mathrm{s}}}}\right]}
$$

$Q_{\mathrm{s}} \quad=$ debit infiltrasi SR $\left(\mathrm{m}^{3} /\right.$ detik)

$\mathrm{F} \quad=$ faktor bentuk bangunan resapan $(\mathrm{m})$

$\mathrm{K}=$ permeabilitas tanah ( $\mathrm{m} /$ detik)

$\mathrm{h} \quad=$ kedalaman air dalam sumur $(\mathrm{m})$

$A_{s} \quad=$ luas penampang sumur $\left(\mathrm{m}^{2}\right)$

Apabila tinggi air dalam sumur $(\mathrm{h})$ lebih besar daripada kedalaman sumur $(\mathrm{H})$, maka terjadi limpasan. Resapan yang terjadi pada saat itu sebesar:

$$
\mathrm{Q}_{\mathrm{s}}=\mathrm{F} . \mathrm{K} \cdot \mathrm{H}
$$

dengan:

$Q_{\mathrm{s}} \quad=$ debit infiltrasi sumur $\left(\mathrm{m}^{3} /\right.$ detik)

$\mathrm{F} \quad=$ faktor bentuk bangunan resapan $(\mathrm{m})$

$\mathrm{K}=$ permeabilitas tanah $(\mathrm{m} /$ detik $)$ 
Faktor geometrik yang mencakup beberapa bentuk dan jenis SR dengan dinding rapat maupun berlubang, selain telah dikembangkan oleh beberapa peneliti sejak 1930-an, telah pula diteliti oleh Sunjoto (1989a). Menurut van Schilfgaarde et al (1974) hidrolika pipa berlubang sangat rumit, maka dalam penelitian ini debit resapan sumur akan diamati secara empiris.

\section{Metodologi Penelitian}

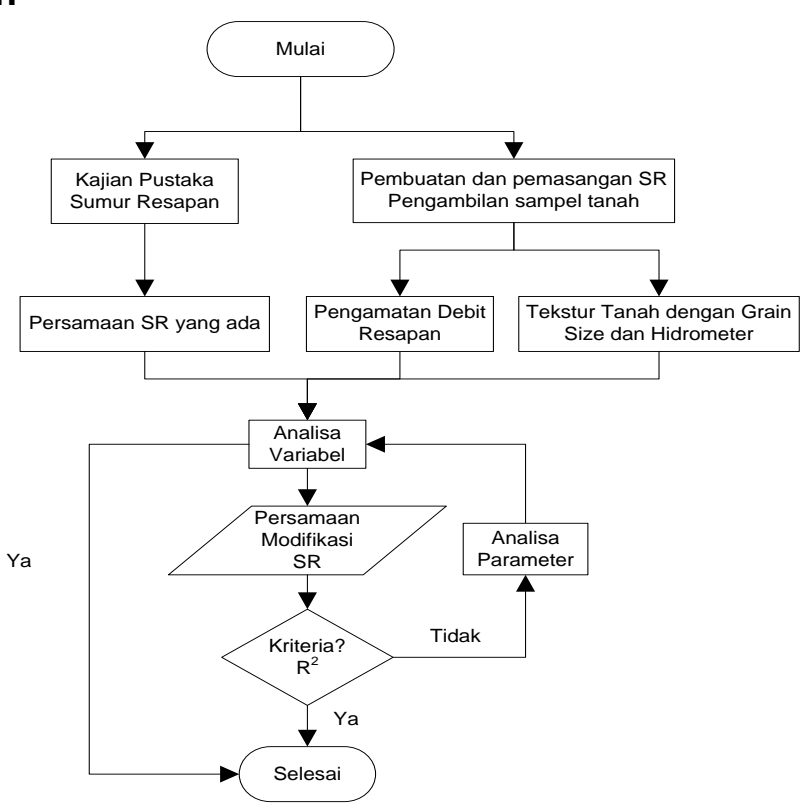

Gambar 2. Diagram alir metoda pelaksanaan penelitian

Sumur resapan yang digunakan dalam penelitian ini berdinding rapat, diameter $50 \mathrm{~cm}$, dan tinggi $90 \mathrm{~cm}$. Pengujian debit resapan sumur dilakukan sebanyak 6 kali dengan periode waktu awal 0 jam (tes-1), 3 jam (tes-2), 18 jam (tes-3), 24 jam (tes-4), 42 jam (tes-5), dan 24 jam (tes-6) dengan terus menerus sumur resapan diisi air tanpa terputus. Pengukuran debit resapan dilakukan setiap kedalaman $10 \mathrm{~cm}, 15 \mathrm{~cm}, 20 \mathrm{~cm}, 25 \mathrm{~cm}, 30 \mathrm{~cm}, 35 \mathrm{~cm}, 40 \mathrm{~cm}, 45$ $\mathrm{cm}, 50 \mathrm{~cm}, 55 \mathrm{~cm}, 60 \mathrm{~cm}, 65 \mathrm{~cm}, 70 \mathrm{~cm}, 75 \mathrm{~cm}, 80 \mathrm{~cm}$, dan $85 \mathrm{~cm}$. Pengujian dilakukan di Kelurahan Bulusan Kecamatan Tembalang Kota Semarang.

Tanah dasar pemasangan SR diambil sebagai sampel untuk mendapatkan gradasi tanah di Laboratorium dengan menggunakan metoda saringan dan hidrometer. Tanah diklasifikasikan menurut penggolongan segitiga tekstur tanah oleh United State Departement of Agriculture (USDA, 2017). Pengamatan resapan SR dibandingkan dengan persamaan SR dengan kedalaman air tetap. Kriteria diterimanya persamaan baru dengan melihat nilai $R$ square $\left(R^{2}\right)$. Nilai $R^{2}$ semakin mendekati 1 model semakin baik.

\section{Hasil dan Pembahasan}

Investigasi tanah dasar SR menunjukkan prosentasi clay $0 \%$, sand $11,73 \%$, dan silt $88,27 \%$. Menurut klasifikasi segitiga tekstur tanah USDA, tekstur tanah tersebut tergolong silt. Debit resapan untuk 6 kali pengujian dapat dilihat pada tabel 1 dan gambar 3 . 
Tabel 1. Debit resapan sumur untuk berbagai kedalaman air

\begin{tabular}{|c|c|c|c|c|c|c|}
\hline $\begin{array}{c}\text { Kedalaman } \\
\text { Air }\end{array}$ & \multicolumn{7}{|c|}{ Debit Resapan $\left(\mathrm{cm}^{3} / \mathrm{dt}\right)$} \\
\hline$(\mathrm{cm})$ & Tes 1 & Tes 2 & Tes 3 & Tes 4 & Tes 5 & Tes 6 \\
\hline 10.00 & 5.67 & 3.95 & 5.73 & 3.99 & 5.02 & 2.88 \\
\hline 15.00 & 6.52 & 4.83 & 7.49 & 5.58 & 5.27 & 3.82 \\
\hline 20.00 & 8.59 & 6.43 & 8.89 & 8.06 & 6.87 & 4.85 \\
\hline 25.00 & 11.86 & 10.21 & 13.13 & 10.08 & 9.60 & 7.08 \\
\hline 30.00 & 22.75 & 12.35 & 15.27 & 12.55 & 12.61 & 11.58 \\
\hline 35.00 & 29.98 & 21.07 & 23.71 & 25.61 & 19.45 & 12.46 \\
\hline 40.00 & 38.41 & 26.16 & 29.93 & 28.82 & 25.29 & 21.93 \\
\hline 45.00 & 45.87 & 36.92 & 41.16 & 35.21 & 38.39 & 29.77 \\
\hline 50.00 & 53.68 & 40.92 & 45.61 & 42.83 & 43.24 & 36.89 \\
\hline 55.00 & 70.93 & 52.09 & 59.07 & 57.25 & 57.48 & 48.24 \\
\hline 60.00 & 93.66 & 81.12 & 86.09 & 79.76 & 80.93 & 73.30 \\
\hline 65.00 & 161.44 & 136.49 & 147.69 & 139.74 & 146.70 & 129.30 \\
\hline 70.00 & 185.67 & 153.03 & 170.15 & 161.84 & 176.71 & 165.78 \\
\hline 75.00 & 242.58 & 230.94 & 252.38 & 242.40 & 262.23 & 235.99 \\
\hline 80.00 & 321.72 & 278.76 & 287.67 & 295.11 & 321.09 & 301.83 \\
\hline 85.00 & 479.13 & 423.50 & 391.25 & 455.97 & 471.53 & 455.55 \\
\hline
\end{tabular}

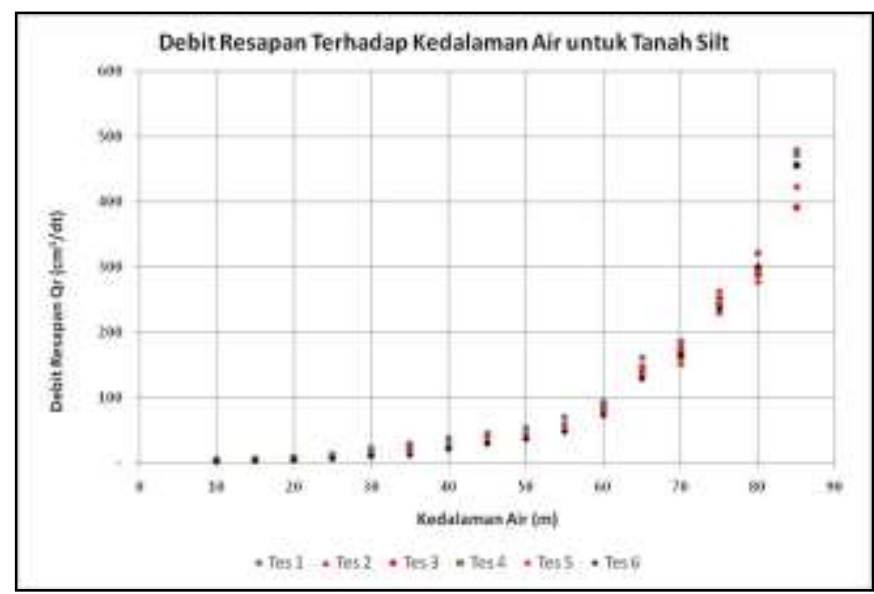

Gambar 3. Debit resapan terhadap kedalaman air

Hasil pengujian resapan menunjukkan semakin tinggi air di dalam SR debit resapan semakin besar. Kenyataan ini menunjukkan semakin besar tekanan hidrostatis dalam sumur resapan akan memperbesar debit resapan. Pengujian resapan yang dilakukan beberapa kali dalam periode waktu sampai 48 jam secara umum menunjukkan kecenderungan menurun (gambar 4). Namun dalam beberapa kondisi menunjukkan naik turun dan belum menunjukkan kondisi resapan stabil. Dimungkinkan untuk tekstur tanah silt dalam periode waktu terserbut belum mencapai jenuh dan pengisian air kedalam sumur tidak konstan. 


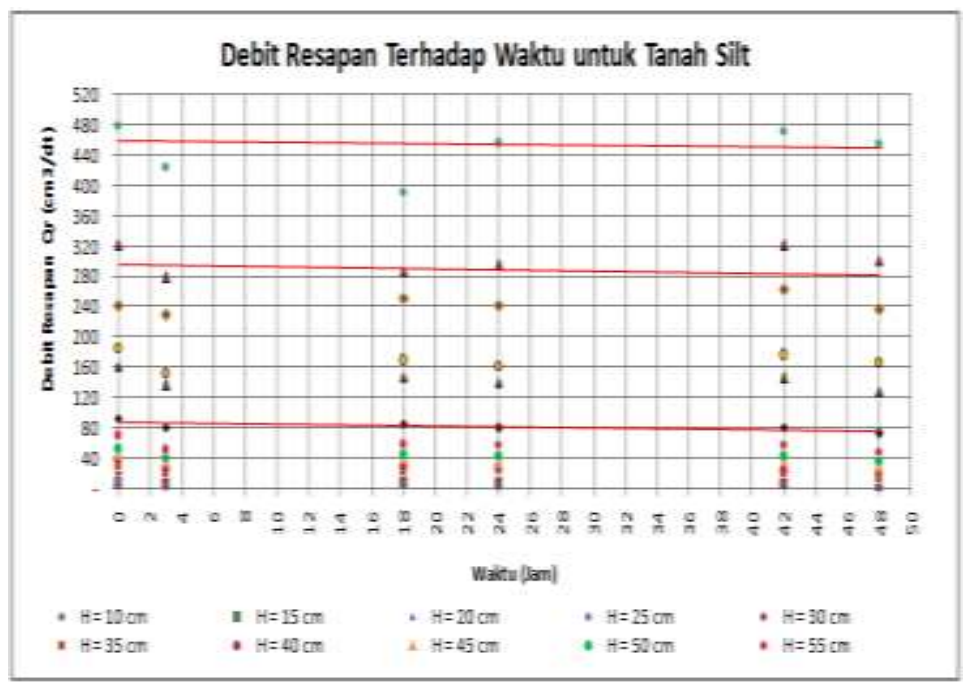

Gambar 4. Debit resapan terhadap waktu

Berdasarkan analisa variabel kedalaman air $(\mathrm{H})$ yang berpengaruh terhadap debit resapan SR pada tekstur tanah dasar silt mengikuti persamaan parabola dengan koefisien $A$, pangkat $B$, dan konstanta 0 sebaimana ditunjukkan persamaan:

$$
\mathrm{Q}=\mathrm{A} \cdot \mathrm{H}^{\mathrm{B}}
$$

Nilai $R^{2}$, koefisien $A$ dan pangkat $B$ untuk tiap pengujian resapan dan tes -1 sampai dengan tes- 6 dapat dilihat pada tabel 2 .

Tabel 2 Nilai $R^{2}$, koefisien dan pangkat

\begin{tabular}{|c|c|c|c|}
\hline Tes & $\mathbf{R}^{2}$ & $\mathbf{A}$ & $\mathbf{B}$ \\
\hline Tes 1-6 & 0.984 & 0.000001 & 4.487 \\
\hline Tes 1 & 0.985 & 0.000002 & 4.300 \\
\hline Tes 2 & 0.989 & 0.000001 & 4.526 \\
\hline Tes 3 & 0.992 & 0.000012 & 3.897 \\
\hline Tes 4 & 0.988 & 0.000001 & 4.678 \\
\hline Tes 5 & 0.993 & 0.000001 & 4.620 \\
\hline Tes 6 & 0.994 & 0.000001 & 4.952 \\
\hline
\end{tabular}

Persamaan terpilih dari 6 kali pengujian adalah persamaan dari penggabungan semua data pengamatan dengan koefisien A sebesar 0,000001 dan pangkat B sebesar 4,487.

\section{Kesimpulan}

Dari hasil analisa data penelitian dapat disimpulkan sebagai berikut;

1. Debit resapan SR dengan diameter 0,50 meter untuk tekstur tanah silt, dapat mengikuti persamaan parabola dalam bentuk persamaan:

$$
\mathrm{Qs}=0,000001 \cdot \mathrm{H}^{4,487}
$$

$$
\begin{aligned}
& \mathrm{H}=\text { kedalaman air }(\mathrm{cm}) \\
& \mathrm{Qs}=\text { debit resapan }\left(\mathrm{cm}^{3} / \mathrm{dt}\right)
\end{aligned}
$$


2. Debit resapan SR akan menurun semakin lama peresapan berlangsung

3. Tanah silt belum mencapai kondisi jenuh dalam waktu peresapan selama 24 jam

\section{Saran}

Penelitian ini diharapkan dapat bermanfaat dalam pengembangan ilmu pengetahuan khususnya bidang sumber daya air yang berhubungan dengan permasalahan hidrologi, yaitu debit resap sumur resapan. Penelitian ini masih sangat awal dalam menyimpulkan hubungan debit resapan dengan kedalaman air. Akan tetapi setidaknya dengan temuan ini untuk jenis tanah silt merupakan formula dasar yang dapat dikembangkan lebih lanjut untuk melaksanakan penelitian lanjutan dengan variasi jenis tanah, diameter dan jenis sumur resapan. Dengan demikian rumus hubungan antara debit resapan dengan kedalaman air dapat diformulasikan secara komprehensif dengan variable jenis tanah, diameter dan jenis sumur resapan dengan dinding berlubang, yang akhirnya akan sangat berguna dalam usaha konservasi air tanah dan sangat penting dalam pengelolaan sumber daya air, khususnya penurunan debit banjir.

\section{DAFTAR PUSTAKA}

- Arif, I., 2009, "Pengaruh Perubahan Penggunaan Lahan Terhadap Karakteristik Hidrologi Daerah Tangkapan Air Waduk Darma, Kabupaten Kuningan, Provinsi Jawa Barat", Tesis, Fakultas Matematika Dan Ilmu Pengetahuan Alam Program Magister IImu Geografi Universitas Indonesia Depok, Desember 2009

- DPU, 1991, "Tata Cara Perencanaan Teknik Sumur Resapan Air Hujan Untuk Lahan Pekarangan", Yayasan LPMB, Bandung

- Forchheimer, 1930, "Hydraulik", Leipzig, Berlin, B.G. Teubner.

- Rahman, H., 2008, "Aplikasi Water Balance Model untuk manajemen air hujan perkotaan: Studi Kasus pada Sub-DAS Sugutamu", Universitas Indonesia, hal. 10

- Sunjoto, 1989a, "Pengembangan Sistem Drainasi di Indonesia", Ceramah IImiah dalam rangka 25 Tahun Jurusan Sipil Fakultas Teknik Sipil dan Perencanaan, Universitas Indonesia, Yogyakarta.

- Sunjoto, 1989b, "Teknik Konservasi Air pada Kawasan Pemukiman", Media Teknik, Edisi Nomor 2 Tahun XI April 1989, ISSN 0216.3012, halaman 77.

- Suripin, 2004, "Sistem Drainase Perkotaan yang Berkelanjutan", Edisi I, Andi, Yogyakarta, halaman 226, 311.

- USDA, 2017, https://www.nrcs.usda.gov/wps/portal/nrcs/detail/soils/survey/

- van Schilfgaarde, J., ed., 1974, "Drainage for Agriculture", Agronomy Series No. 17, American Society of Agronomy, Madison, WI. 